\title{
Association of Viral Load and CD4+ count with Infection of Intestinal Emerging Parasites in HIV Patients
}

Leticia Eligio-García ${ }^{1}$, Apolinar Cano-Estrada ${ }^{1}$, Cesar Cruz $^{2}$ and Enedina Jiménez-Cardoso ${ }^{1 *}$

${ }^{1}$ Laboratory of Parasitology. Children Hospital of Mexico. Cuauhtémoc, Doctores, 06720, CDMX, México

${ }^{2}$ Clínica Especializada Condesa, Cuauhtémoc, Hipódromo Condesa, 06170, CDMX, México

\begin{abstract}
Parasitic infections are common cause of diarrhea in patients with HIV combined with symptoms such as fatigue, nausea, intestinal cramps and flatulence. In HIV seropositive patients, the disease is often prolonged and severe. Parasites most frequently found in biological samples of HIV infected people are Cryptosporidium spp., Microsporidium and Giardia, Isospora and Cyclospora. The purpose of this study was to know the prevalence of parasitic infections in HIV infected patients and to establish the relationship with CD4 counts and viral load. 109 stool three serial samples from HIV seropositive patients were collected and analyzed by Zinc sulphate centrifugal floatation method and then stained with Ziehl-Neelsen Staining procedure. A " $t$ " distribution analyses was made. A low viral load, CD4 count greater than 500, the absence of diarrhea and the ART treatment are not indicative in all cases of free parasitic infection.
\end{abstract}

Keywords: Emerging parasites; HIV; Viral load; CD4 count, ART

\section{Background}

A medical condition called acquired immunodeficiency syndrome (AIDS) arose in 1981, it was characterized by severe immunodeficiency and rapidly, was extended around the world [1]. The infection is caused by HIV-1 RNA virus that belongs to retroviridae family. The disease is characterized by replication of HIV-1 with destruction of CD4 lymphocytes [2] and decrement of immune system response, leaving the patient exposed to tumors as Kaposi's sarcoma and primary lymphoma of the brain, as well as opportunistic and emerging infections caused by bacteria, fungi, viruses and parasites [3].

The classification system of HIV infections are divided into clinical categories, based on the number of lymphocytes and viral load $[4,5]$. The number of helper $\mathrm{T}$ cells reflects the stage of infection in the patient and this parameter is used to determine the damaged to the immune system. A normal count of helper T cells in blood (cells per $\mathrm{mm}^{3}$ ) in a healthy adult who is not infected with HIV can normally vary between 500 and 1,500 cells $/ \mathrm{mm}^{3}$ of blood and infection with HIV reduces the count of helper $\mathrm{T}$ lymphocytes and this cause that people begin to get opportunistic infections or cancers more recurrently as their count is reduced.

The viral load test measures the amount of HIV found in a quantity of blood. This test does not show how much damage suffered by the immune system, but can provide an idea of how quickly the infection is likely to progress. A high viral load, even when the person has a good count of helper $\mathrm{T}$ cells, indicating the possibility that the person get worse quickly and develop AIDS if not start immediately a medical treatment [6]. Currently there are some antiretroviral therapies (ART) that effectively control HIV replication and allow evaluating a treatment response [7] however in the developing countries the absence of ART therapy causes that patients continue to suffer the consequences of opportunistic parasites.

Diarrhea is the presence of liquid stool at least twice a day and is the most common symptom in people infected with HIV, the prevalence and severity vary depending on the developmental stage of the disease [8] and it could be due to treatment or infections of opportunistic pathogens. Parasitic infections are a common cause of diarrhea in these individuals and they are often more prolonged and severe than healthy people [9] and even could be combined with symptoms such as fatigue, nausea, intestinal cramps and flatulence, which causes extra complications to viral infection.

Emerging parasites have been isolated frequently from immunodepressed individuals due to several factors as climate change, conditions in a population, human migration, growth of the world population, ecological change, the resistance of microorganisms to antibiotics among others [10]. Parasites most frequently found in biological samples of HIV infected people are Cryptosporidium spp., Microsporidium and Giardia, Isospora and Cyclospora [11-15].

The purpose of this study was to know the association of CD4 counts and viral load with parasitic infections on HIV infected patients with recent diagnosis.

\section{Materials and Methods}

\section{Study design}

A comparative cross-sectional study was conducted from October 2014 and November 2015. 109 three serial stool samples from HIV seropositive patients, who were diagnosed recently (about six months ago), were collected. They were woman and men over 18 years old, who were diagnosed and treated with ART at specialized clinic Condesa, which attend residents from CDMx, in center of Mexico. This research project was approved by the Research Ethics Committee of the Children Hospital, where the analysis of the samples was carried out.

\section{Coproparasitoscopic analysis}

Three samples of feces were collected in sterile containers for

*Corresponding author: Enedina Jiménez-Cardoso, Laboratory of Parasitology Children Hospital of Mexico, Dr. Márquez 162, Cuauhtémoc, Doctores 06720 CDMX. México, Tel: 0155 55884019; E-mail: Jimenezce@yahoo.com.mx

Received November 14, 2016; Accepted December 09, 2016; Published December 16, 2016

Citation: Eligio-García L, Cano-Estrada A, Cruz C, Jiménez-Cardoso E (2016) Association of Viral Load and CD4+ count with Infection of Intestinal Emerging Parasites in HIV Patients. J AIDS Clin Res 7: 644. doi: 10.4172/2155-6113.1000644

Copyright: (c) 2016 Eligio-Garcia L, et al. This is an open-access article distributed under the terms of the Creative Commons Attribution License, which permits unrestricted use, distribution, and reproduction in any medium, provided the original author and source are credited. 
transportation on serial days and they were analyzed to find parasitic structures stained with lugol. All samples were processed by Zinc sulphate centrifugal floatation method [16]: About $1 \mathrm{~g}$ of the stool specimen was emulsified in 10 parts of water and it was strained through wire gauze. The filtrate was collected in a tube and centrifuged at 2,500 $\mathrm{rpm}$. The supernatant was discarded and the sediment was resuspended in water, this step was repeated three times. To the sediment, 3-4 $\mathrm{ml}$ of $33 \%$ Zinc sulphate solution was added, it was mixed well and it was filled with $\mathrm{ZnSO}_{4}$ solution, about half an inch of the rim. A cover slip was placed on the surface and after one minute it was transferred to a glass slide, it was mixed with a drop of lugol and observed in the light microscope brand Olympus BH-2 with 40x and 100x objectives.

\section{Ziehl-Neelsen staining procedure}

Spread a quantity of stool sample in a central area of a slide using a continuous rotational movement. Heat Fixation of smear was carried out. After dried the smear was cover with carbol fuchsin stain, after incubation at $60^{\circ} \mathrm{C}$, a Wash off the stain with clean water was made. Smear was covered with $3 \% \mathrm{v} / \mathrm{v}$ acid-alcohol for $2 \mathrm{~min}$ or until the smear is sufficiently decolorized. Malachite green stain was added during 1-2 min and wash with clean water. The sample was dried and examined microscopically, using the 100x oil immersion objective [17].

\section{CD4+ lymphocyte count}

Quantification of CD4+ lymphocyte subpopulations in peripheral blood was performed by identifying surface antigens using flow cytometry. The TritestTM anti-CD4-FITC/ CD8 PE/CD3 PerCP kit (BD Biosciences, USA) and truCountTM (BD Biosciences, USA) tubes were used, thus enabling cell count in absolute figures by FACSCaliburTM flow cytometer (BD Biosciences, USA) [18].

\section{Viral load count}

The Versant HIV-1 RNA 3.0 bDNA system (Bayer Corporation, USA) test was used for direct quantification of type-1 human immunodeficiency virus (HIV-1) RNA in plasma from individuals with HIV-1 by amplification of the signal emitted by the nucleic acid, using a Bayer System 340 bDNA Analyzer (USA) [19].

\section{Results}

99/109 male and 10/109 female samples were analyzed, 13/109 samples had diarrhea when samples were took and 5/109 tested positive to multiple parasitic infection. All the patients lived in an urban environment in the city and had received their diagnosis in the last four months before taking the sample. They attended the clinic regularly and were under treatment with ART in different steps (Table 1).

Table 1 shown the relationship between CD4 count and viral load with presence of intestinal parasites. 36/109 total samples were positive to parasitic infection, this was no related to diarrhea, since in both diarrheic and solid samples parasites were present.

Infection by parasites was also observed indistinctly with ART and without it.

CD4 count is useful to determine the condition of immune system, in this case $7 / 36(19.5 \%)$ were immunocompetent $(\mathrm{CD} 4>500 \mathrm{cell} / \mu \mathrm{L})$, 7/36 (19.5\%) presented mild immunosuppression (CD4 350-499 cell/ $\mu \mathrm{L}), 12 / 36$ (33.3\%) presented advanced immunosuppression (CD4 200349 cell $/ \mu \mathrm{L})$ and $10 / 36(27.7 \%)$ presented severe immunosuppression $(\mathrm{CD} 4<200$ cell $/ \mu \mathrm{L})$.

Viral load $>30,000$ copies per $\mathrm{mL}$ are considered with low probability to develop AISD and death and 13/36 (36.1\%) are in this case, 22 cases were undetectable and 16 of them had values above 30000 copies.

After staining with Ziehl Neelsen procedure all samples, results (Figure 1) showed that 19/109 (17.43\%) presented Microsporidium spp., 3/109 samples (2.75\%) Cryptosporidium spp. 3/109 samples (2.75\%) Entamoeba histolytica, 4/109 (3.66\%) Giardia intestinalis and in $3 / 109$ samples $(2.75 \%)$ helminths were identified. found in 3 samples $(2.75 \%)$ and isolated positive cases were found and were grouped in the category of others, among them: E. coli, Uncinaria, H. nana and $E$. nana (11.92\%).

Relation between CD4 count and viral load showed in Figure 2 shows that presence of parasites is independent of values of CD4 $(\mathrm{P}=0.88872535)$ and viral load $(\mathrm{P}=0.52779596)$, hence both parameters did not significantly differ between the parasite and non parasite patients.

\section{Conclusion}

Mexico is the third place in cases of AIDS in Latin America and Mexico City has the highest incidence in the country. Samples observed in this study corresponding mainly to male patients, consistent with reports about the male/female ratio of AIDS cases diagnosed in 2011 in Mexico City was 4.6 cases in men for each case in women, whereas the ratio in people who remained HIV positive was 3.3 cases in this year [17], This is observed in this study because the majority of samples received and analyzed corresponded to male patients.

Immunosuppressed HIV patients are characterized because the immune cells are attacked by the virus causing a significant decrease in defense cells, enabling them to develop opportunistic microorganisms. The prevalence of intestinal parasitic infections in HIV-infected patients from developing countries ranges from $12 \%$ to $38 \%$ [18]. In this case the frequency was $36 / 109$ (33.07\%), this is consistent with some previous reports [19], the variation in the prevalence of parasites could be due to geographic area, but in present study all patients lived in the same urban region.

The parasite most frequently found was Microsporidium spp., which has been considered one of the most important opportunists causing diarrhea, difficult to eliminate because there is no specific treatment to combat infection. The identification of Microsporidium presents the difficulty of requiring specific acid resistant stain to observe the spores in feces. A high prevalence of Microsporidium, based on microscopic examination, was found in Thai HIV-infected patients. This confirms its importance in HIV-infected/AIDS patients and the necessity for stool evaluation in all HIV-infected patients [20,21].

The presence of enteric pathogens was not associated with sex, diarrheal symptoms and status of ART. As already mentioned, most of the samples belonged to male patients, which is determined because HIV infection is higher proportionally in men than in women and this fact is irrelevant for this study.

Although parasites can alter the intestinal mucosa and cause diarrhea, in patients infected with HIV should be considered that diseases that compromise the immune system by themselves cause diarrhea, in addition in some cases ART treatment cause tis symptom as a side effect, so caution should be used to establish the relation between parasitic infection with diarrhea in HIV patients, due to diarrhea is not a determining factor of parasitic infection.

The prevalence of intestinal parasites found to be higher in patients that do not receive an ART treatment [22]. Increasing the immune 
Citation: Eligio-García L, Cano-Estrada A, Cruz C, Jiménez-Cardoso E (2016) Association of Viral Load and CD4+ count with Infection of Intestinal Emerging Parasites in HIV Patients. J AIDS Clin Res 7: 644. doi: 10.4172/2155-6113.1000644

Page 3 of 4

\begin{tabular}{|c|c|c|c|c|c|}
\hline Age/gender & Diarrhea & ART & CD4 count & Viral load & Parasite \\
\hline $56 / \mathrm{M}$ & + & EFV-FTC & 129 & 40 & E. coli, G. intestinalis \\
\hline $22 / \mathrm{M}$ & + & $\mathrm{N}$ & 320 & 502720 & Microsporidium sp. \\
\hline $41 / \mathrm{M}$ & + & EFV & 148 & 174511 & Microsporidium sp. \\
\hline $31 / \mathrm{M}$ & $\mathrm{N}$ & EFV & 450 & 100000 & Microsporidium sp. \\
\hline $41 / \mathrm{M}$ & + & TUD-EFV & 543 & 40 & Microsporidium sp. \\
\hline $30 / \mathrm{M}$ & $\mathrm{N}$ & $\mathrm{N}$ & 843 & 105000 & E.coli \\
\hline $25 / \mathrm{M}$ & $\mathrm{N}$ & $\mathrm{N}$ & 418 & 65408 & Microsporidium sp. \\
\hline $25 / \mathrm{M}$ & $\mathrm{N}$ & $\mathrm{N}$ & 318 & 10272 & Microsporidium sp. \\
\hline $22 / \mathrm{M}$ & $\mathrm{N}$ & $\mathrm{N}$ & 118 & 426787 & Microsporidium sp. \\
\hline $31 / \mathrm{M}$ & $\mathrm{N}$ & 3TC-EFV & 671 & 0 & G. intestinalis \\
\hline 49/M & + & ATV-RTV-TDF & 680 & 300000 & E. coli \\
\hline $44 / \mathrm{M}$ & $\mathrm{N}$ & $\mathrm{N}$ & 222 & 298068 & Microsporidium sp. \\
\hline $36 / \mathrm{M}$ & $\mathrm{N}$ & 3TC-AZT-EFV & 255 & 0 & E. coli \\
\hline $44 / \mathrm{M}$ & $\mathrm{N}$ & $\mathrm{N}$ & 287 & 0 & E. coli \\
\hline $40 / \mathrm{M}$ & $\mathrm{N}$ & $\mathrm{N}$ & 459 & 11804117 & E. coli \\
\hline 48/M & $\mathrm{N}$ & TDF-FTC-EFV & 230 & 40 & Microsporidium sp. \\
\hline 29/M & $\mathrm{N}$ & TDF-FTC-EFV & 12 & 365068 & E. nana \\
\hline $26 / F$ & $\mathrm{~N}$ & TDF-FTC-EFV & 26 & 405310 & E. coli \\
\hline $28 / \mathrm{M}$ & $\mathrm{N}$ & TDF-FTC-EFV & 550 & 4919 & E. coli \\
\hline $32 / \mathrm{M}$ & $\mathrm{N}$ & TDF-FTC-EFV & 448 & 603777 & E. coli \\
\hline $53 / \mathrm{F}$ & $\mathrm{N}$ & $\mathrm{N}$ & 53 & 0 & Microsporidium sp. \\
\hline $30 / F$ & $\mathrm{~N}$ & $\mathrm{~N}$ & 131 & 14716 & E. nana \\
\hline $25 / F$ & $\mathrm{~N}$ & TDF-FTC-EFV & 5 & 439879 & Cryptosporidium \\
\hline $43 / \mathrm{M}$ & $\mathrm{N}$ & TDF-FTC-EFV & 426 & 19794 & Uncinaria \\
\hline $25 / \mathrm{M}$ & $\mathrm{N}$ & TDF-FTC-EFV & 236 & 240 & Microsporidium sp. \\
\hline $17 / \mathrm{M}$ & $\mathrm{N}$ & TDF-FTC-EFV & 562 & 11381 & E. coli \\
\hline $30 / \mathrm{M}$ & $\mathrm{N}$ & TDF-FTC-EFV & 284 & 184114 & Microsporidium sp. \\
\hline $25 / \mathrm{M}$ & $\mathrm{N}$ & TDF-FTC-EFV & 400 & 50 & G. intestinalis \\
\hline $36 / \mathrm{M}$ & $\mathrm{N}$ & TDF-FTC-EFV & 240 & 0 & Toxocara \\
\hline $26 / M$ & + & $\mathrm{N}$ & 294 & 23186 & Microsporidium sp. \\
\hline $30 / \mathrm{M}$ & $\mathrm{N}$ & TDF-FTC-EFV & 94 & 69 & Microsporidium sp. \\
\hline $56 / \mathrm{M}$ & $\mathrm{N}$ & TDF-ABC-LPV & 263 & 0 & Microsporidium sp. \\
\hline $49 / \mathrm{M}$ & $\mathrm{N}$ & TDF-FTC-EFV & 618 & 43451 & Microsporidium sp. \\
\hline $30 / \mathrm{M}$ & $\mathrm{N}$ & $\mathrm{N}$ & 294 & 23186 & G. intestinalis \\
\hline $25 / \mathrm{M}$ & $\mathrm{N}$ & TDF-FTC-EFV & 94 & 69 & Cryptosporidium sp. \\
\hline $36 / \mathrm{M}$ & $\mathrm{N}$ & $\mathrm{N}$ & 263 & 0 & H. nana \\
\hline
\end{tabular}

Table 1: Profile of samples analyzed in this study and the relationship between CD4 count (cell/ $\mu \mathrm{L})$ and viral load (copies/mL) with presence of intestinal parasites. 36 positive samples of 109 total samples are shown. The average age of the patients was 34 and the gender (M; male/F; female), was predominant (11.11\%). There was no significant relationship with the presence of parasites and diarrhea; with diarrhea $(+)$, without diarrhea (N). 24/36 patients was under one or more of the following anti-retroviral drugs: tenofovir (TDF), emtricitabine (FTC), azidothymidina (AZT), lamivudine (3TC), efavirenz (EFV), (NRTI), atazanavir (ATV), ritonavir (RTV), abacavir $(A B C)$ and lopinavir. Viral load $>30,000$ copies per $\mathrm{mL}$ are considered with low probability to develop AISD and death. 0 means that value was undetectable

20

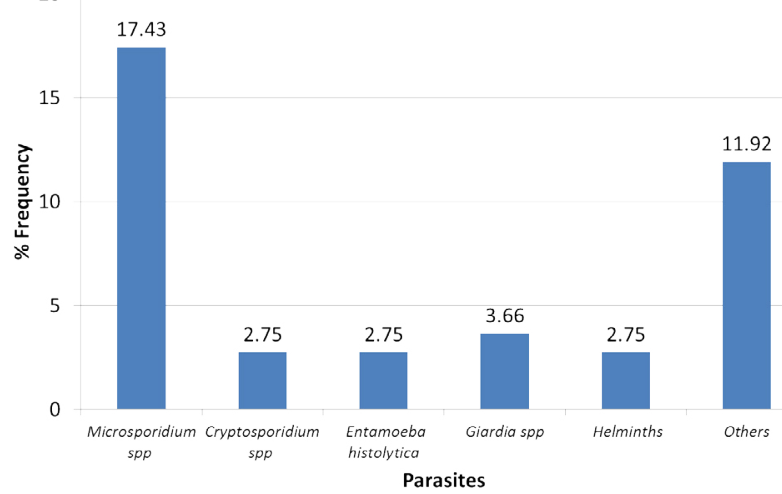

Figure 1: Frequency of parasites infecting adult individuals with HIV.

The frequency of parasites found in feces of patients infected with HIV is observed. The parasite most frequently found was Microsporidium spp. $(17.43 \%)$. Isolated positive cases were found and were grouped in the category of others, among them: E. coli, Uncinaria, H. nana and E. nana. status of HIV infected patients with anti-retroviral therapy may help to reduce acquisition of parasites. In this case, there is not a significant relationship between la presence of parasites and the ART, perhaps because these patients have received their diagnosis in the last four months but it is not known how long they have been infected, so maybe ART has not had the desired effect.

The CD4 count and viral load values are very useful for determining the person's immune status, ART efficiency, and prognosis of AIDS infection development. The results showed that regardless of the immunological status of the individual parasitic infection could be present and although the viral load was very high or undetectable the same case was observed.

Results show that the tools that are currently known for the monitoring of parasitosis are insufficient and it is necessary to perform coprological analysis in HIV infected patients, since parameters such as low viral load, CD4 count greater than 500, the absence of diarrhea and the ART treatment are not indicative in all cases of free 
Citation: Eligio-García L, Cano-Estrada A, Cruz C, Jiménez-Cardoso E (2016) Association of Viral Load and CD4+ count with Infection of Intestinal Emerging Parasites in HIV Patients. J AIDS Clin Res 7: 644. doi: 10.4172/2155-6113.1000644

Page 4 of 4

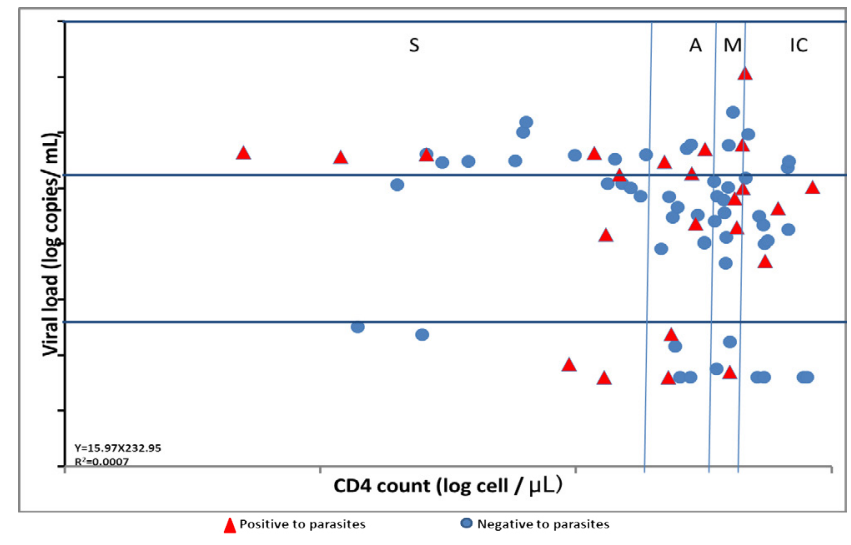

Figure 2: Relation between CD4 count and viral load with presence of parasites.

Values are shown in logarithmic scale and red circles represent presence of parasites, these are distributed throughout the scale independently of the values of cd4 and viral load indicating that there is no relationship between the three parameters. IC: Immunocompetent, S, A and M indicate severe, advanced and mild immunosuppression respectively.

parasitic infection and can cause serious complications to the patient's deteriorated state affecting the quality of life.

\section{References}

1. Masur H, Michelis MA, Greene JB, Onorato I, Stouwe RA, et al. (1981) An outbreak of community-acquired Pneumocystis carinii pneumonia: Initial manifestation of cellular immune dysfunction. N Engl J Med 305: 1431-1438.

2. Rozenbaum W, Coulaud JP, Saimot AG, Klatzmann D, Mayaud C, et al. (1982) Multiple opportunistic infection in a male homosexual in France. Lancet 1: 572-573.

3. Hymes KB, Cheung T, Greene JB, Prose NS, Marcus A, et al. (1981) Kaposi's sarcoma in homosexual men-a report of eight cases. Lancet 2: 598-600.

4. Patnaik P, Jere CS, Miller WC, Hoffman IF, Wirima J, et al. (2005) Effects of HIV1 serostatus, HIV-1 RNA concentration and CD4 cell count on the incidence of malaria infection in a cohort of adults in rural Malawi. J Infect Dis 192: 984-991.

5. Tatfeng YM, Ihongbe JC, Okodua M, Oviasogie E, Isibor J, et al. (2007) CD4 count, viral load and parasite density of HIV positive individuals undergoing malaria treatment with dihydroartemisinin in Benin City, Edo state, Nigeria. J Vector Borne Dis 44: 111-115.

6. Nettles RE, Kieffer TL, Kwon P, Monie D, Han Y, et al. (2005) Intermittent HIV-1 viremia (Blips) and drug resistance in patients receiving HAART. JAMA 293: 817-829.
7. WHO, UNAIDS (2008) Report on the global AIDS epidemic. UNAIDS, Geneva.

8. Arenas-Pinto A, Certad G, Ferrara G, Castro J, Bello MA, et al. (2003) Association between parasitic intestinal infections and acute or chronic diarrhoea in HIV-infected patients in Caracas, Venezuela. Int J STD AIDS 14: 487-492.

9. Wuhib T, Silva TM, Newman RD, Garcia LS, Pereira ML, et al. (1994) Cryptosporidial and microsporidial infections in human immunodeficiency virusinfected patients in north-eastern Brazil. J Infect Dis 170: 494-497.

10. Musey L, Hughes J, Schacker T, Shea T, Corey L, et al. (1997) CytotoxicT-cell responses, viral load, and disease progression in early human immunodeficiency virus type 1 infection. N Engl J Med 337: 1267-1274.

11. Pollock KG, Young D, Smith HV, Ramsay CN (2008) Cryptosporidiosis and filtration of water from Loch Lomond, Scotland. Emerg Infect Dis 14: 115-120.

12. Fedorko DP, Hijazi YM (1996) Application of molecular techniques to the diagnosis of microsporidial infection. Emerg Infect Dis 2: 183-191.

13. Rivero-Rodríguez Z, Hernández A, Bracho Á, Salazar S, Villalobos R (2013) Prevalence of intestinal microsporidia and other intestinal parasites in HIV positive patients from Maracaibo, Venezuela. Biomedica 33: 538-545.

14. Nateghi Rostami M, Nikmanesh B, Haghi-Ashtiani MT, Monajemzadeh M, Douraghi M, et al. (2014) Isospora belli associated recurrent diarrhoea in a child with AIDS. J Parasit Dis 38: 444-446.

15. Chokephaibulkit K, Wanachiwanawin D, Tosasuk K, Vanprapa N, Chearskul S (2001) A report case of Cyclospora and Cryptosporidium mixed infection in a HIV-negative child in Thailand. J Med Assoc Thai 84: 589-592.

16. Parameshwarappa KD, Chandrakanth C, Sunil B (2012) The prevalence of intestinal parasitic infestations and the evaluation of different concentration techniques of the stool examination. J Clin Diagn Res 6: 1188-1191.

17. CENSIDA (2012) Informe Nacional de Avances en la Lucha contra el SIDA, México 26-89.

18. Kaniyarakkal V, Mundangalam N, Puduvail Moorkoth A, Mathew S (2016) Intestinal parasite profile in the stool of HIV positive patients in relation to immune status and comparison of various diagnostic techniques with special reference to cryptosporidium at a tertiary care hospital in South India. Adv Med 2016: 3564359 .

19. Jiménez-Cardoso E, Eligio-García L, Cano-Estrada A, Cortés-Campos A Medina-Sansón A, et al. (2013) Frequency of emerging parasites in HIVIAIDS and oncological patients stool by coprological and molecular analysis. Adv Infect Dis 3: 162-171.

20. Viriyavejakul P, Nintasen R, Punsawad C, Chaisri U, Punpoowong B, et al (2009) High prevalence of Microsporidium infection in HIV-infected patients. Southeast Asian J Trop Med Public Health 40: 223-228.

21. Sokolova OI, Demyanov AV, Bowers LC, Didier ES, Yakovlev AV, et al. (2011) Emerging microsporidian infections in Russian HIV-infected patients. J Clin Microbiol 49: 2102-2108.

22. Missaye A, Dagnew M, Alemu A (2013) Prevalence of intestinal parasites and associated risk factors among HIVIAIDS patients with pre-ART and on-ART attending dessie hospital ART clinic, Northeast Ethiopia. AIDS Res Ther 10: 7. 